\title{
ESTRATÉGIAS DE LEITURA, SOB O OLHAR DE DUAS DOCENTES NO ENSINO FUNDAMENTAL I
}

\author{
READING STRATEGIES IN ELEMENTARY EDUCATION
}

\author{
Aline Neves Gomes ${ }^{1}$ \\ Nara Cristine Thomé Palácios Cechella²
}

\begin{abstract}
RESUMO: O presente artigo traz uma reflexão docente acerca das questões relacionadas às Estratégias de Leitura no Ensino Fundamental I, em uma Rede de Ensino do Município de Içara. Tentou-se apresentar a importância das estratégias de leitura, e como podem auxiliar na compreensão leitora dos alunos. O artigo teve o objetivo de verificar de que forma o professor desenvolve a leitura de forma significativa, identificando a importância das estratégias de leitura dos vários tipos de gêneros textuais. Para construir o referencial teórico, foram usadas e pesquisadas algumas ideias de alguns autores, entre eles destacam-se: Emmel (2003), Freire (1989), Leffa (1996), documentos norteadores como Proposta Pedagógica Curricular de Içara, o PPP (Projeto Político Pedagógico) da escola e o Projeto Anual Escolar. A coleta dos dados foi realizada por meio de um questionário, com duas professoras que responderam às questões, conforme seus conhecimentos e suas práticas docentes vivenciadas. $\mathrm{O}$ artigo mostrou que a escola investigada possui um grande interesse sobre a leitura, mas quando colocado em prática, fica visível que o assunto se mostra vago, além de as professoras também apresentarem a falta de argumentos e embasamentos teóricos sobre o assunto.
\end{abstract}

PALAVRAS-CHAVE: Compreensão Leitora. Ensino Fundamental. Língua Portuguesa. Estratégias de leitura. Gêneros Textuais.

ABSTRACT: This article presents a teacher reflection about the issues related to Reading Strategies in Elementary School I, in a Teaching Network of the city of Içara. It was tried to present the importance of reading strategies, and how they can help in the reading comprehension of the students. The article aimed to verify how the teacher develops reading significantly ways, identifying the importance of reading strategies of the various types of textual genres. In order to construct the theorical reference, some ideas of some authors were used and researched, among them Emmel (2003), Freire (1989), Leffa (1996), guiding documents like Curricular Pedagogical Proposal of Içara (PPP - Political Pedagogical Project)

\footnotetext{
1 Acadêmica do Curso de Pedagogia, da Universidade do Extremo Sul Catarinense - UNESC. E-mail: alineneves26@hotmail.com.

${ }^{2}$ Professora Mestre em Educação, Especialista em Didática e Metodologia do Ensino, Graduada em Letras, docente efetiva da rede pública de ensino de Santa Catarina, na Escola de Educação Básica Engenheiro Sebastião Toledo dos Santos e docente da Universidade do Extremo Sul Catarinense - UNESC. E-mails: nara@unesc.net, naractpc@gmail.com ou narapalacios@ hotmail.com.
}

Saberes Pedagógicos, Criciúma, v. 2, nº1, janeiro/junho 2018.- Curso de Pedagogia- UNESC 
of school and the annual school project. The data were collected through a questionnaire, with two teachers who answered the questions, according to their knowledge and their teaching practices. The article showed that the school investigated has a great interest in reading, but when it is put into practice, it is visible that the subject is vague, besides the teachers also present the lack of arguments and basic theoretical background about the theme.

KEYWORDS: Reading Comprehension. Elementary Education. Portuguese Language. Reading Strategies. Textual Genres.

\section{INTRODUÇÃO}

A leitura faz parte do processo formativo e contribui para que as emoções aflorem no sentido de desenvolver a criatividade, a criticidade, e a autonomia dentre outras potencialidades que, por sua vez, contribuem para a melhoria da qualidade de vida. Porém, muitas pessoas, incluindo alguns professores, ignoram a importância do processo de formação do leitor no período escolar, desperdiçando oportunidades de construir outras possibilidades de aprendizagem que poderiam auxiliar estudantes a compreender melhor o mundo em que vivem, enfim, a se expressarem melhor.

O presente artigo, cujo tema é "Estratégias de Leitura sob o olhar de Duas Docentes no Ensino Fundamental I", surgiu a partir da problematização sobre os critérios adotados nas estratégias de leitura aplicadas pelas docentes de duas turmas de uma escola municipal de Içara, sendo uma de $3^{\circ}$ ano e a outra de $5^{\circ}$ ano, trazendo à tona as dificuldades de associar teoria à prática de leitura no processo de ensino e aprendizagem.

Foram adotadas como norte, duas questões: o que as educadoras entendiam como leitura, bem como a importância das estratégias de leitura dos vários gêneros textuais e de que forma um(a) professor(a) poderia trabalhar as estratégias de leitura em sala de aula. Com base nesses dois questionamentos, foi elaborado o instrumento de pesquisa e coleta de dados.

Como objetivo geral, buscou-se compreender como as estratégias de leitura podem auxiliar na compreensão leitora dos(as) alunos(as) desta escola que, em princípio, trabalha com um projeto multidisciplinar anual. Como objetivos específicos - por meio da pesquisa sobre o que seria estratégia e com quais conceitos de leitura e gêneros textuais trabalhar -, verificar de que forma as professoras desenvolvem a leitura de forma significativa na sala de aula e

Saberes Pedagógicos, Criciúma, v. 2, nº1, janeiro/junho 2018.- Curso de Pedagogia- UNESC 
identificam a importância das estratégias da leitura dos diversos tipos de gêneros textuais aplicados nas turmas de $3^{\circ}$ e $5^{\circ}$ anos, turmas em que esta acadêmica atuou durante o período do estágio no ano anterior.

Justifica-se esta pesquisa pelo destaque dado ao tema para os(as) profissionais da educação, os quais estão em constante discussão sobre as fragilidades no processo de compreensão leitora, uma vez que não existe uma fórmula pronta, mas diretrizes, ideias a serem aplicadas, mas que nem sempre são alcançadas nas metodologias pensadas pelas docentes. Para tanto, foi preciso investigar como são constituídas e elaboradas as estratégias de leitura e os critérios de utilização das possíveis técnicas de compreensão leitora na escola em cujas turmas foram pesquisadas.

A leitura, por si só, já é um assunto polêmico e, falar sobre estratégias de como seria o "ler bem", poderá vir a confirmar que professores(as) sempre enfrentaram situações com os(as) alunos(as) em sala de aula que não conseguiram resolver eficientemente; situações essas que, possivelmente, com a falta de interesse dos(as) estudantes, resistência na execução de atividades e dificuldade de quaisquer outras naturezas persistirem, fazem com que não consigam compreender e interpretar o que leem.

$\mathrm{O}$ interesse por esse tema ocorreu no momento em que o cotidiano educativo dos educadores e educadoras foram apontados nas disciplinas do Curso de Pedagogia da UNESC como os responsáveis pelo processo de construção do(a) aluno(a)/leitor(a) e como os(as) nem sempre compreendem e trabalham de forma eficaz este processo, daí a necessidade de pesquisar acerca do problema apresentado.

As observações empíricas realizadas em sala de aula, enquanto estagiária, mostrou que os(as) alunos(as) não conseguem, na maioria das vezes, interpretar o que leem, eles(as) apenas decodificam os códigos linguísticos. Mas, a leitura não é apenas algo para decodificar, leitura é algo que se leva para a vida toda, como problematizar-se-á mais adiante.

Pode-se dizer que ler é compreender e interpretar textos diversos, isso contribui para a autonomia do ser humano. Também se supõe que o(a) leitor(a) seja um processador ativo do texto, que a leitura possibilite transmitir hipóteses que levem à construção da compreensão do que foi lido.

Saberes Pedagógicos, Criciúma, v. 2, nº1, janeiro/junho 2018.- Curso de Pedagogia- UNESC 
Nesse sentido, foram observados alguns pontos, os quais se tentou problematizar no questionário aplicado, como: será que os(as) professores(as) estariam usando estratégias de leitura eficientemente? A aula está sendo usada para atividades mecânicas, sem os devidos comandos do(a) docente para alcançarem os objetivos das atividades? Será que usam técnicas diferentes para chamar a atenção do(a) aluno(a)?

O artigo está organizado de forma a apresentar, primeiramente, o trabalho de pesquisa falando de sua significância no âmbito educativo e social. A seguir, apresenta-se a leitura como indispensável no processo de ensino e aprendizagem, pautando-se nos conceitos e concepções da mesma, a partir de: Paulo Freire (1989), Vilson Leffa (1996), Kato (1987).

Quanto aos resultados, são apontadas as possíveis causas das dificuldades de leitura e como as educadoras/turmas com que foram feitas a pesquisa podem reinventar criar, intervir na práxis para que esta deixe de ser um mero mecanismo de decoreba, como instrumentos de estudos para provas, exames e afins, mas que se efetive de fato como instrumento de conhecimento e transformação.

$\mathrm{O}$ artigo finaliza apresentando estratégias de leitura usadas, as quais poderiam ser aperfeiçoadas e utilizadas por estas educadoras, a fim de abordar a leitura em sala de aula, utilizando ferramentas tecnológicas, afinal estamos na era da informação, onde o livro virtual também passou a ser uma importante ferramenta e, com isso, possa enriquecer o processo de leitura nos alunos.

Em síntese, buscou-se com essa pesquisa, destacar quais são as estratégias de leitura usadas no Ensino Fundamental da escola escolhida, possibilitando a educadores(as), outras pessoas envolvidas no processo de ensino e aprendizagem subsídios para enriquecer e qualificar sua prática educativa.

\section{LEITURA: UM PROCESSO HISTÓRICO, SOCIAL E CULTURAL}

Ler é uma habilidade básica essencial ao ser humano, pois a leitura abre horizontes às pessoas de histórias distintas. Em sociedades baseadas na informação, a habilidade da leitura não é simplesmente necessária, mas, sobretudo, uma exigência; e o ser humano, como alguém em construção, está sempre buscando este conhecimento. Portanto, a leitura é o meio mais

Saberes Pedagógicos, Criciúma, v. 2, nº1, janeiro/junho 2018.- Curso de Pedagogia- UNESC 
eficiente de enriquecimento e desenvolvimento da personalidade. É um passaporte para a vida e para a sociedade. É na infância que se adquire o hábito de ler, porque nesta fase o seu cognitivo tem todas as potencialidades e disponibilidades para o prazer da leitura (EMMEL, 2003).

No decorrer da história, a leitura era entendida no âmbito educativo, simplesmente como um ato de decodificação, em que se convertiam letras em sons. Em função dessa visão, a escola formou uma quantidade muito grande de leitores inaptos a realmente compreenderem os textos lidos, embora os decodificassem.

Para Emmel (2003), o verdadeiro ato de ler é um processo de atribuição de sentido ao texto, isto é, a partir de conhecimentos que já possui, o leitor interage com o texto, construindo significados. Assim, os objetivos que levam alguém a ler podem ser os mais variados. Algumas pessoas leem porque estão buscando informação, outras porque precisam aprender algo ou ainda por outras diversas razões, porém, a capacidade de ler criticamente. Por isso, compreende-se o ato de ler como um processo de atribuição de sentido ao texto. A partir de conhecimentos que já possui, o leitor interage com o texto, construindo significados. Considerando a variedade de objetivos que levam alguém a ler, sua importância e relevância, o ensino da leitura exige muito mais do que a escola e os(as) educadores(as) vêm proporcionando até então.

Nesta perspectiva, Freire (1989) relata sua experiência de mundo, fundamental na atribuição de sentido ao processo de apropriação de leitura:

\begin{abstract}
Mas, é importante dizer, a 'leitura' do meu mundo, que me foi sempre fundamental, não fez de mim um menino antecipado em homem, um racionalista de calças curtas. A curiosidade do menino não iria distorcer-se pelo simples fato de ser exercida, no que fui mais ajudado do que desajudado por meus pais. E foi com eles, precisamente, em certo momento dessa rica experiência de compreensão do meu mundo imediato, sem que tal compreensão tivesse significado malquerenças ao que ele tinha de encantadoramente misterioso, que eu comecei a ser introduzido na leitura da palavra. A decifração da palavra fluía naturalmente da "leitura" do mundo particular. Não era algo que se estivesse dando super postamente a ele. Fui alfabetizado no chão do quintal de minha casa, à sombra das mangueiras, com palavras do meu mundo e não do mundo maior dos meus pais. O chão foi o meu quadro-negro; gravetos, o meu giz. (FREIRE, 1989, p. 09)
\end{abstract}

Conforme os Parâmetros Curriculares Nacionais de Língua Portuguesa (BRASIL, 1997), um(a) leitor(a) competente é aquele(a) que compreende o que lê; que possa aprender a ler também, o que não está escrito, identificando elementos implícitos que estabeleça relações

Saberes Pedagógicos, Criciúma, v. 2, nº1, janeiro/junho 2018.- Curso de Pedagogia- UNESC 
entre o texto que lê e outros textos já lidos, que saiba que vários sentidos podem ser atribuídos a um texto; que consiga justificar e avaliar a sua leitura a partir da localização de elementos discursivos. De acordo com Freire (1989):

\begin{abstract}
Os alunos não tinham que memorizar mecanicamente a descrição do objeto, mas apreender a sua significação profunda. Só apreendendo-a seriam capazes de saber, por isso, de memorizá-la, de fixá-la. A memorização mecânica da descrição do elo não se constitui em conhecimento do objeto. Por isso, é que a leitura de um texto, tomado como pura descrição de um objeto é feita no sentido de memorizá-la, nem é releitura, nem dela, portanto resulta o conhecimento do objeto de que o texto fala. (FREIRE, 1989, p. 12).
\end{abstract}

De acordo com os autores Freire (1989) e Emmel (2003), fica claro que a leitura é um processo de interação entre o(a) leitor(a) e o texto, ou seja, um(a) leitor(a) ativo(a), pois sempre se deve ter um objetivo para guiar a leitura, já que sempre lemos para algo ou alguém, com algum objetivo, para se ter alguma informação, seguir uma pauta ou instruções para se realizar uma determinada atividade, como cozinhar, conhecer as regras de um jogo, ler um jornal, etc.

\title{
2.1 Conceitos de Leitura
}

A leitura não é algo pronto e acabado, nem algo fragmentado e sem sentido, ela é fruto de um processo com características próprias, e tem relação com as propriedades do sistema de escrita alfabético do português brasileiro.

Parafraseando Freire (1989), a leitura pode ser conceituada como um registro da matéria cotidiana, guardada pela memória, é um olhar sobre o pensamento do outro, é viajar no mundo, no espaço e no tempo sem sair do lugar.

Segundo a Proposta Pedagógica Curricular de Içara Ensino Fundamental (BRASIL, 2015, p. 46), onde não há o conceito de leitura, mas sim, práticas de leitura, escrita, escuta e fala, encontra-se o seguinte:

Quando se fala em leitura, imediatamente, recorremos à ideia do texto escrito, entretanto, estamos a todo o momento fazendo leituras da vida, seja a leitura de uma expressão facial, ou uma imagem, por exemplo. Portanto, sabendo da importância da leitura é que a escola tem compromisso de possibilitar aos estudantes os diversos modos de ler os mais variados gêneros, o que garantirá a construção da competência leitora.

Saberes Pedagógicos, Criciúma, v. 2, nº1, janeiro/junho 2018.- Curso de Pedagogia- UNESC 
$\mathrm{O}$ ato de ler implica algo muito maior que a simples busca de informações. Implica entender a leitura como algo que exige do sujeito o uso de suas capacidades intelectuais superiores como, por exemplo, a atenção voluntária, que é a condição básica para qualquer situação de aprendizagem. Implica em compreender a linguagem como o princípio básico da leitura em neste sentido, Marcuschi (2007) afirma que são os usos da língua que fundam a língua e não o contrário.

De acordo com os Parâmetros Curriculares Nacionais de Língua Portuguesa (BRASIL, 1997, p. 57), “a leitura, como prática social, é sempre um meio, nunca um fim. Ler é resposta a um objetivo, a uma necessidade pessoal”. Segundo Leffa (1996, p. 24), a leitura funcionaria como um processo que faz com que o leitor e o texto reajam entre si, em um processo de interação para formar um terceiro elemento que é a compreensão. Para o autor, "ler é um fenômeno que ocorre quando o leitor, que possui uma série de habilidades, entra em contato com o texto, essencialmente um segmento da realidade que se caracteriza por refletir outro segmento."

Segundo Kato (1987), decodificação é a capacidade de identificar um signo gráfico por um nome ou por um som. Esta capacidade ou competência linguística consiste no reconhecimento das letras ou signos gráficos e na tradução dos signos gráficos para a linguagem oral ou para outro sistema de signo. Assim sendo, a leitura é um processo que depende de várias condições: do grau de maturidade do(a) leitor(a), da complexidade do texto, do objetivo da leitura, do conhecimento do assunto dado e do estilo individual do leitor.

\footnotetext{
A leitura é ainda uma operação cognitiva em que entre o texto e o leitor se produz um caminho perceptivo dependente da fisiologia do olhar, em que observações e fixações condicionam o leitor, em que o conhecimento prévio do mundo (linguístico, textual e do mundo) conduz o leitor a uma dada compreensão do texto lido; seria ainda atividade crítica, de desenvolvimento de uma inteligência dialética em que ao se interrogar o texto se responde com o interrogar de outro texto: o leitor. (KATO, 1987, p. 70).
}

Parafraseando Kato (1987), entende-se que, em leitura, dois fatores conjuntos são importantes: a habilidade de conhecimento das palavras escritas e as habilidades que permitem a compreensão auditiva. Porém, ambos os fatores são necessários e nenhum deles é suficiente para dar conta da compreensão da leitura.

Saberes Pedagógicos, Criciúma, v. 2, nº1, janeiro/junho 2018.- Curso de Pedagogia- UNESC 


\section{SABERES PEDAGÓGICOS}

Revista do Curso de Graduaçāo de Pedagogia - Unesc

ISSN 2526-4559

\section{ESTRATÉgias PEDAgógiCAS DE LEITURA PARA FORMAR BONS LEITORES}

Para Cagneti (1986), o processo de leitura demanda a participação efetiva do(a) leitor(a), a quem cumpre ativar seu conhecimento de mundo, fazer inferências, empenhar-se de fato para construir os sentidos do que está sendo processado por seu aparato neurofisiológico e cognitivo.

Neste sentido, para fazer o contato inicial e desenvolver o interesse da criança pela leitura, é também necessário que o(a) professor(a) se auto eduque como leitor(a), mostrando a função da leitura (informação ou deleite). Desta forma, ele(a) fará com que a criança entenda que, na leitura, encontre informações novas, simbolização daquilo que vê, que pensa ou que sente, interpretando as imagens e outros signos não-verbais presentes nos textos. $\mathrm{O}(\mathrm{A})$ docente, então, recruta o conhecimento prévio dos(as) alunos(as) a respeito do tema em questão, lendo para a criança (primeiros anos), dramatizando, mudando o tom de voz, expressões faciais, gestos, enfim, incentiva a leitura silenciosa ou em voz alta, alternando, nesta última situação, estratégias como a leitura declamada, dramatizada (RIZZATTI, 2004).

Para Solé (1998, p. 70), toda leitura é orientada pelos objetivos e finalidades que o(a) leitor(a) tem ao realizá-la, e estes objetivos determinam a escolha de procedimentos estratégias de leitura - que tornarão o processo mais eficaz e, por isso, acrescenta que o(a) professor(a) deve sempre:

- Compreender os propósitos implícitos e explícitos da leitura. Que/Por que/Para que tenho que ler?

- Ativar e aportar à leitura os conhecimentos prévios relevantes para o conteúdo em questão. O que sei sobre o conteúdo do texto?

- Dirigir a atenção ao fundamental, em detrimento do que pode parecer mais trivial.

- Avaliar a consistência interna do conteúdo expressado pelo texto e sua compatibilidade com o conhecimento prévio e com o "sentido comum". Este texto tem sentido?

Saberes Pedagógicos, Criciúma, v. 2, nº1, janeiro/junho 2018.- Curso de Pedagogia- UNESC 
- Comprovar continuamente se a compreensão ocorre mediante a revisão e a recapitulação periódica e a auto interrogação. Qual é a ideia fundamental extraída do texto?

- Elaborar e provar inferências de diversos tipos, como interpretações, hipóteses e previsões e conclusões. Qual poderá ser o final desta história? E, neste contexto, é imprescindível estimular a tanto a prática individual quanto a coletiva.

Existem inúmeras estratégias de leitura a que Solé (1998) enfatiza que dão suporte ao processo de apropriação da leitura, facilitação a compreensão de quem lê e que podem ser invocadas nas três etapas da leitura:

- Antes, permitindo situar o(a) leitor(a) diante da leitura, instigando-o(a) a assumir papel ativo no processo;

- Durante, permitindo construir uma interpretação que auxilie na resolução de problemas; e

- Depois da leitura, predispondo-se a unificar as etapas anteriores de forma concreta. Para Cavéquia (2002, p. 27), as estratégias são necessárias para que haja a apropriação do saber escrito, e por isso ter claros os objetivos que ser quer com a leitura é muito importante para o sucesso do(a) leitor(a). Estes objetivos orientadores da leitura podem ser vários:

\footnotetext{
a) ler para obter uma informação específica;

b) ler para obter uma informação geral;

c) ler para seguir instruções (de montagem, de orientação geográfica);

d) ler para aprender;

e) ler para revisar um texto;

f) ler para construir repertório - temático ou de linguagem - para produzir outros textos;

g) ler oralmente para apresentar um texto a uma audiência (numa conferência, num jornal);

h) ler para praticar a leitura em voz alta para uma situação de leitura dramática, de gravação de áudio, de representação;

i) reler para verificar se houve compreensão;

j) ler por prazer estético.
}

Verifica-se assim que, ter clareza dos objetivos que orientam a leitura possibilitará selecionar os procedimentos mais adequados para realizá-la. 
A reeducação na leitura muitas vezes se faz pelas técnicas e habilidades de leitura que inconscientemente o(a) educando(a) desenvolve ao ler. Deste modo, os(a) professores(as) devem utilizar estratégias para que o(a) leitor(a) consiga inconscientemente processar a leitura. "Estratégias são suspeitas inteligentes, embora arriscadas, sobre o caminho mais adequado que devemos seguir" (SOLÉ, 1998, p.69).

Leitura não é só prazer, pois, quando transformada em dever de casa ou em matéria de prova, seu efeito é devastador: forma gerações de inimigos da leitura. O desafio do(a) professor(a) comprometido(a) em formar bons(as) leitores(as) é seduzir o(a) jovem e a criança para a leitura. Por este motivo, uma dos papéis do(a) professor(a) é oferecer a possibilidade de variados textos, como: quadrinhos, revistas, anúncios de jornais, bilhetes, cartas, rótulos de embalagens, bulas de remédios, cartazes, poemas, contos, charges, etc. Com isso, o professor estará proporcionando o acesso ao mundo da leitura.

O estudo da língua deve ser realizado como um todo, pois não é eficaz fragmentar a língua em gramática, literatura e redação sendo que o envolvimento do(a) professor(a) é a base desse processo que apresentará certamente bons resultados.

Mas, como fazer para tornar a leitura uma atividade prazerosa? É possível afirmar que a resposta a esta pergunta encontra-se nos Parâmetros Curriculares Nacionais de Língua Portuguesa (BRASIL, 1997, p. 58):

Para tornar alunos bons leitores - para desenvolver, muito mais do que a capacidade de ler, o gosto e o compromisso com a leitura -, a escola terá de mobilizá-los internamente, pois aprender a ler (e também ler para aprender) requer esforço. Precisará fazê-los achar que a leitura é algo interessante e desafiador, algo que, conquistado plenamente, dará autonomia e independência. Precisará torná-los confiantes, condição para poderem se desafiar a "aprender fazendo". Uma prática de leitura que não desperte e cultive o desejo de ler não é uma prática pedagógica eficiente.

Assim, considera-se que a capacidade de ler criticamente, de forma prazerosa garante ao indivíduo condições de interferir no meio em que está inserido, podendo, inclusive, transformar a realidade.

\section{METODOLOGIA, APRESENTAÇÃO E ANÁLISE DE DADOS}

Saberes Pedagógicos, Criciúma, v. 2, nº1, janeiro/junho 2018.- Curso de Pedagogia- UNESC 
A abordagem da pesquisa foi qualitativa, e a metodologia utilizada para a elaboração deste artigo consistiu em algumas etapas, sendo a primeira delas a escolha da escola, das turmas a serem observadas e as professoras. Foi selecionada uma escola da Rede Pública Municipal de Ensino, em Içara, sul de Santa Catarina, município onde esta pesquisadora reside e trabalha. As turmas selecionadas foram um $3^{\circ}$ e um $5^{\circ}$ anos, onde atuavam as educadoras entrevistadas. O motivo destas escolhas deu-se porque esta acadêmica atuou durante o seu período de estágio no ano anterior, nestas duas turmas, especificamente.

A pesquisa qualitativa, então, caracteriza-se pela tentativa de uma compreensão detalhada dos significados e características situacionais apresentadas pelos entrevistados. Argumenta-se que esta forma de pesquisa é aplicável para levantamento de hipóteses e que seus métodos de coleta de dados e análises são apropriados para a pesquisa exploratória [...] (PINHEIRO, 2010, p. 20). Pressupõe-se que o uso de questionários permite verificar com qualidade a problemática apresentada inicialmente, porque, sob vários ângulos, a populaçãoalvo expõe o que pensa e como vê estes problemas a partir de diferentes pontos de vista. Neste caso, o público-alvo desta pesquisa foram as duas educadoras.

A segunda etapa foi a análise dos documentos da escola (Projeto Político Pedagógico e Projeto Anual Escolar), a fim de relacioná-los às práticas docentes e conhecer quais as estratégias de leitura eram utilizadas pelas docentes nas aulas de Língua Portuguesa. Durante esta etapa, foi encontrado um Blog da escola, em que havia postagens relacionadas ao tema, o qual foi trazido à análise neste artigo.

Além disso, como última etapa, utilizou-se um questionário para a coleta dos dados na pesquisa de campo, mas, antes de sua aplicação, houve uma conversa informal com as duas professoras, pois foi considerada a importância da união dos procedimentos usados, a fim de se obter o conhecimento por escrito, de próprio punho, além dos registros da acadêmica. As ações foram assim planejadas, pois o método, como Barros e Lehfeld (2000) tratam, seria essa visão abstrata de uma ação, e a metodologia, a visão concreta da operacionalização. Portanto, a técnica de coleta de dados foi feita por uma conversa informal que antecedeu a entrega de um questionário, em que foram contempladas algumas questões abertas e fechadas para facilitar a análise dos registros escritos.

Saberes Pedagógicos, Criciúma, v. 2, nº1, janeiro/junho 2018.- Curso de Pedagogia- UNESC 
Dando prosseguimento à primeira etapa, para que a autora desta pesquisa tivesse mais segurança na análise dos dados, foi solicitado o acesso ao $\mathrm{PPP}^{3}$ (PROJETO POLÍTICO PEDAGÓGICO, 2017) da escola e ao Projeto Anual Escolar de 2017, a fim de ler o que havia sobre o tratamento dado às questões de Leitura, e se estavam ligadas apenas à disciplina de Língua Portuguesa ou a outras disciplinas, a questões gerais ou mesmo a de outro projeto em particular. Foi bastante difícil e demorado este período de espera, pois questões internas da escola, as quais não serão trazidas a este artigo, dificultaram significativamente esta etapa.

Com o PPP e o Projeto em mãos, finalmente, pode-se passar à leitura e análise com mais calma. Para surpresa da autora, no PPP da escola, a leitura é citada em apenas 07 (sete) momentos. A primeira menção feita à Leitura foi na página 04, item 5. Dos Fins e Objetivos da Educação, 5.1Fins, que tratam sobre Leis e Resoluções. Logo a seguir dos documentos, a LDB é citada:

A LDB está em função do objetivo maior do Ensino Fundamental, que é o de proporcionar a formação básica para a cidadania, mediante: Desenvolvimento da capacidade de aprender, tendo como meio básico o pleno domínio da leitura e do vocábulo. (grifo nosso)

A segunda menção é encontrada na página 07 , item 5.5 onde são tratados os Objetivos da escola: “[...] Continuar reduzindo o índice de reprovação, por meio de práticas de leitura, de escrita, de interpretação, de recuperação de estudos, de atendimento individualizado e especializado".

A terceira, quarta e quinta menções, estão no item 5.6 Metodologia, página 08:

[...] Acontecerá quinzenalmente em dias e horários alternados momentos de leitura através de jornais, mensagens, gibis, poemas, músicas e pensamentos para alunos e funcionários com duração de 30 minutos; [...]

Realizar campanhas de arrecadação de livros e gibis, para sanar as dificuldades de leitura, escrita e interpretação;

Conscientização para reduzir o índice de reprovação por meio de aulas de reforço na informática, leituras na biblioteca e em sala de aula, correio, sarau, divulgação de história coletiva, biblioteca móvel, produção textual etc.[...]. (grifos nossos)

A sexta menção é feita em 8.4.1 Regime Disciplinar, no item I, letra c, página 23:

\footnotetext{
${ }^{3}$ Projeto Político Pedagógico e Projeto Anual Escolar “O Mundo é feito de Histórias. A nossa é a gente que faz”, da escola pesquisada (2017) que, aqui, será referenciado como Projeto Anual Escolar. Por questões éticas, o nome da escola não será mencionado neste trabalho.
}

Saberes Pedagógicos, Criciúma, v. 2, nº1, janeiro/junho 2018.- Curso de Pedagogia- UNESC 
$\mathrm{O}$ aluno que transgredir as normas contidas no presente Regimento, conforme a gravidade e/ou a reincidência dos fatos, estará sujeito às seguintes sanções aplicadas pela direção: [...]

III - suspensão das atividades de classe, por no máximo 5 (cinco) dias letivos, sem prejuízo de conteúdos e avaliações, podendo receber atividades alternativas e a ele cabendo inteirar-se dos conteúdos ministrados no período: [...]

Em caso de mais do que um dia, a suspensão será cumprida externamente, nos moldes descritos na tabela a seguir e com a realização de uma atividade educativa: pesquisa, leitura ou outras. Esta atividade será determinada pelo professor ou pela Equipe Técnica Pedagógica. (grifo nosso)

A sétima - e última menção -, é feita em 9.1.4, onde é tratado sobre o papel do Bibliotecário ou Auxiliar de Biblioteca:

\section{Compete ao Bibliotecário ou Auxiliar de Biblioteca:}

Atendimento aos alunos e professores;

Catalogar os volumes adquirido ( ic ) ou doados;

Zelar pelo bom funcionamento da biblioteca e seu acervo;

Promover estratégias e/ou atividades que incentivem a prática social da leitura.

O Projeto Anual Escolar, que deveria tratar da leitura, traz um breve parágrafo, intitulado Momento da leitura:

O momento da leitura é realizado quinzenalmente em toda a escola. Nesse momento a biblioteca disponibiliza a caixa de livros de acordo com a idade série. Cada aluno escolhe um livro que é reservado para as suas leituras e um marca texto com a foto do aluno para marcar a página de leitura. A escola reserva o tempo de 30 minutos para leitura com música de acordo e 15 minutos para a discussão da mesma. Nesse momento o educador escolhe alguns alunos para falar sobre a sua leitura.

Mais uma vez, portanto, para a surpresa da autora, a questão da leitura é apenas mencionada neste pequeno parágrafo.

A partir da leitura dos documentos, foi possível perceber que a leitura é trazida apenas como "um momento" e não como uma prática com estratégias definidas, as quais deveriam permear todas as demais disciplinas e atividades intrínsecas, desenvolvidas no ambiente escolar. Não há, sequer, explicações específicas de como os(as) alunos(as) serão levados a desenvolver suas capacidades leitoras, ou seja, a terem o domínio pleno da leitura.

Embora a escola pareça preocupada em acabar com índice de reprovação, não é aconselhável depositar todas as expectativas apenas nas atividades leitoras, pois há outras habilidades e competências a serem exercitadas e desenvolvidas entre os estudantes no rol de disciplinas curriculares, usando, inclusive, os inúmeros gêneros textuais. Nos documentos 
analisados, leva-se a acreditar que realizando práticas de leitura e escrita, por meio das aulas de reforço, saraus literários, produções textuais, recuperações de conteúdos, entre outros, proporcionará a formação básica dos(das) alunos(as), desenvolvendo a capacidade de aprender a escrever e ler. Mas, a formação de um(a) aluno(a) vai além destas práticas desenvolvidas apenas na disciplina de Língua Portuguesa.

Especificamente sobre o Projeto Anual Escolar, que no ano de 2017 foi intitulado como “O mundo é feito de Histórias. A nossa é a gente quem faz!", ele inclui a leitura, mas não trata especificamente sobre ela. Nele, aparece que, entre as atividades realizadas, uma vez na semana, por 45 minutos, os(as) alunos(as) praticam suas habilidades leitoras em diferentes suportes de gêneros: gibis, livros de contos, revistas, entre outros. No projeto, que possui como subtemas: Valores éticos, morais, sociais; Meio ambiente: conceito e ações de sustentabilidade; Pluralidade cultural e Identidade existe uma observação sobre a elaboração de ações de cada turma, indicando saída de estudos como exemplo de uma das atividades a serem desenvolvidas, seguida de datas comemorativas e algumas ações coletivas como a responsabilidade pela atualização do mural com as séries/anos responsáveis e seus(as) respectivos(as) professores(as). Também há um quadro com uma escala mensal e os nomes dos(as) funcionários(as) responsáveis pela "hora do conto".

Além disso, há um trecho que traz o Ato Cívico como um momento de leitura:

Acontece quinzenalmente de $1^{\circ}$ ao $5^{\circ}$ anos e quinzenalmente $6^{\circ}$ ao $9^{\circ}$ anos. Durante o ato cívico, são passados recados importantes e discutidos assuntos democráticos. De frente às bandeiras, os estudantes cantam o hino Nacional e municipal. (PROJETO DE LEITURA, 2017, p. 2)

Em seguida, outro destaque é dado ao Bibliosesc, um caminhão com acervo bibliográfico que visita a escola de 15 em 15 dias:

Quinzenalmente recebemos nas proximidades da escola o caminhão do Bibliosesc, uma biblioteca móvel, que atendente (sic) a (sic) comunidade do bairro e a (sic) escola. (PROJETO DE LEITURA, 2017, p. 2)

Mais uma vez aparece uma lista de Datas Importantes que, na verdade, trata de um cronograma de feriados, reuniões, Conselhos de Classe e mais quatro itens: Simulado, Gincana do Conhecimento, Jetramp e Feira Solidária, com suas respectivas datas e horários, mas sem detalhes de que tratam qual a metodologia de trabalho ou quaisquer outras informações.

Saberes Pedagógicos, Criciúma, v. 2, nº1, janeiro/junho 2018.- Curso de Pedagogia- UNESC 
Contudo, esse problema chama a atenção, pois esta pesquisadora trabalha na referida escola há quatro anos, e percebeu que os(as) alunos(as) estão cada dia menos interessados(as) na leitura, mesmo com o projeto.

Mas, a escola escolhida para a pesquisa parecia estar preocupada com a questão da leitura. Entretanto, mesmo com todas as possibilidades de leitura oportunizadas aos(às) alunos(as), os(as) professores(as), em uma conversa informal para definir o tema deste artigo, admitiram que seus(as) alunos(as) não conseguem fazer relação com o que leem; que eles(as) podem ler várias vezes mas, ao serem questionados(as) sobre o que leram, não conseguem dizer do que tratou a leitura.

Cabe registrar que, durante a pesquisa, foi identificado um Blog (fig. 1) desta escola na internet, em que havia uma "aba" relacionada ao papel social da leitura na vida de um indivíduo. O texto, de 2010, trata do projeto como um "incentivador à prática social de leitura". Em outra aba, há uma relação de textos desenvolvidos pelos(as) alunos(as), publicados como forma de divulgação e incentivo. As postagens são de 2012. O Blog não se encontra mais em atividade, mas poderia ser uma das atividades práticas a serem resgatadas em um mundo informatizado e que chama a atenção de crianças e jovens, cada vez mais voltados às tecnologias e suas redes sociais.

Figura 1: Imagem captada do Blog da escola

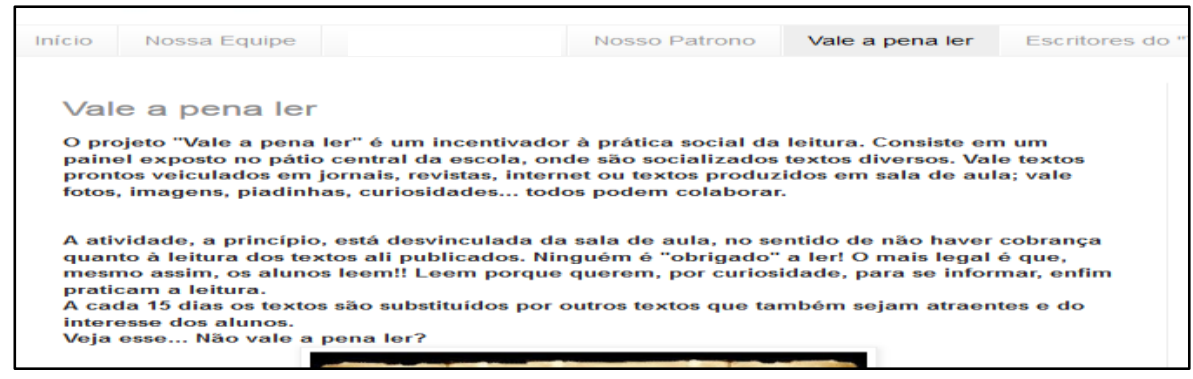

Fonte: Dados da Pesquisa.

Após as leituras dos documentos, os quais foram norteadores para este artigo, seguiu-se à próxima etapa, a de aplicação dos questionários às duas docentes das séries selecionadas para pesquisa. Por questões éticas, nem a escola nem as professoras foram 
identificadas. Para referir-se às docentes, foram utilizados os termos Professora 1 e Professora 2. Antes de aplicar o instrumento de pesquisa, houve uma conversa informal com as docentes que lecionam nas turmas selecionadas, explicado o motivo da pesquisa, os objetivos e apresentado o Termo do Sigilo e Compromisso.

Como a intenção foi a de ter acesso aos registros fieis sobre as práticas das docentes, não foram feitas entrevistas formais, mas sim, aplicado um instrumento elaborado com 16 questões, sendo 10 fechadas (múltipla escolha) e 06 abertas (dissertativas). As primeiras questões fechadas (múltipla escolha) tratavam da faixa etária das professoras. A segunda questão tratava de formação acadêmica; a terceira sobre categoria funcional, seguidas sobre o regime de trabalho, e tempo de serviço na rede municipal de educação. A sexta questão questionava em qual série atuavam, a seguinte questionava se trabalhavam em outra unidade de ensino. A oitava questão tratava se a escola contava com equipamentos de tecnologia, seguida da solicitação sobre o que mais dificultava o desenvolvimento da prática pedagógica ao trabalhar com atividades de leitura e, caso utilizasse o laboratório de informática com os alunos, quais ações desenvolviam.

Nas questões abertas (dissertativas), a décima primeira questão tratava de quais gêneros textuais costumava utilizar em suas aulas, a fim de desenvolver atividades de leitura, interpretação e compreensão. A décima segunda questionava sobre o que são estratégias de leitura e se a docente conseguiria explicar ou indicar, pelo menos, duas estratégias utilizadas em sua práxis pedagógica. A décima terceira solicitava informações a respeito de como trabalhavam as estratégias de leitura, e se era/é possível perceber que os(as) alunos(as) estão conseguindo avançar e apresentar resultados nas atividades que requerem compreensão e interpretação leitora. As três últimas questões abordavam sobre como trabalhavam as estratégias de leitura em sala de aula, aplicando diferentes gêneros textuais em suas atividades; o que viria a ser uma "leitura significativa" e, finalmente, na décima sexta, se elas acreditavam ser possível medir a capacidade de compreensão leitora de um(a) aluno(a).

Os questionários foram aplicados no dia 10 de Abril de 2017. A Professora 1 entregou no dia 11 de Abril de 2017; no entanto, a Professora 2 alegou que havia esquecido em casa e só entregou no dia 17 de Abril de 2017. 
Sobre este comportamento da Professora 2, pelo contato anterior, é possível fazer uma leitura e levantar uma questão a ser refletida no seguinte sentido: ela se esqueceu, de fato, ou tentou pesquisar algo para melhor responder às questões? Levantou-se, então, uma hipótese: a de que quando um questionário não é preenchido no mesmo instante, é possível avaliar que o(a) entrevistado(a) - ou respondente - possa se sentir constrangido(a) ou intimidado(a) e querer parecer mais eficiente em suas respostas, conseguindo tempo hábil para poder pesquisar e melhorar seus argumentos. Desta forma, teria respostas mais convincentes, pois como não entregou no mesmo dia, entende-se que a mesma quis um tempo maior, para sim, responder algo mais concreto.

Passar-se-á, a seguir, à análise das respostas das duas docentes. Definiu-se que as análises serão individualizadas, para que o(a) leitor(a) conheça o perfil de cada uma. Em seguida, far-se-á uma comparação dos itens que mais chamaram a atenção da pesquisadora.

\section{PROFESSORA 1:}

A professora 1 é Especialista, pertence à faixa etária de 35 a 45 anos. É docente efetiva com 40 horas-aula semanais. Trabalha na Rede Municipal de Ensino há mais de 15 anos. Atualmente leciona em uma turma de $3^{\circ}$ ano e não atua em nenhuma outra unidade de ensino.

A Professora 1 relatou que em sua prática pedagógica usa alguns equipamentos de tecnologias como: computador, datashow, rádio, televisão e DVD. Ao perguntar o que mais dificulta o desenvolvimento da prática pedagógica ao trabalhar com atividades de leitura, a professora relatou que falta tempo para que possa se dedicar a preparar atividades de leitura.

No laboratório de informática, ao ser questionado sobre quais ações desenvolvia, a mesma disse que usa softwares educacionais para a produção de gêneros diversos, mas não citou nenhum exemplo.

Sobre quais gêneros textuais ela costuma utilizar em suas aulas, a fim de desenvolver atividades de leitura, interpretação e compreensão, ela registrou que usa poemas, fábulas, histórias em quadrinhos, receitas, cantigas de rodas e textos informativos.

Para a Professora1, 'Estratégia de leitura' significa "antecipar a leitura que está por vir, levar o estudante a ter conhecimentos prévios sobre determinado assunto. Ao relatar Saberes Pedagógicos, Criciúma, v. 2, nº 1, janeiro/junho 2018.- Curso de Pedagogia- UNESC 
duas estratégias de leitura que desenvolvia em suas aulas, citou apenas uma, que seria a leitura silenciosa e oral". Ao ser questionada sobre qual a forma que ela trabalha as estratégias de leitura, se é possível perceber que os(as) alunos(as) estão conseguindo avançar e apresentar resultados nas atividades que requer compreensão e interpretação leitora, ela relatou que os(as) estudantes não apresentam resultados nas atividades que leitura e compreensão, e acredita que precisa adaptar atividades e encontrar novas estratégias e alternativas. Para a professora 1 , " $a$ leitura significativa é aquela em que o aluno a vê como uma atividade de busca em que se trabalha o texto e se transforma a informação em conhecimento".

Quando questionada sobre a possibilidade de medir a capacidade de compreensão leitora de um(a) aluno(a), ela respondeu que "é algo bem complexo. Vai depender da idade, da turma, do tipo de texto trabalhado".

\section{PROFESSORA 2:}

A professora 2 é Graduada, pertence à faixa etária de 45 a 55 anos. É docente efetiva, com 40 horas-aula semanais. Trabalha na Rede Municipal de Ensino há mais de 15 anos. Atualmente, leciona em uma turma de $5^{\circ}$ ano e não atua em nenhuma outra unidade de ensino. Ela relata que em sua prática pedagógica usa alguns equipamentos de tecnologias como: computador, lousa digital, datashow, rádio, televisão e DVD. Ao ser questionada sobre o que mais dificulta o desenvolvimento da prática pedagógica ao trabalhar atividades de leitura, a professora disse: "em nossa unidade escolar temos algumas práticas de leitura bastante significativas, mas o que vejo como uma dificuldade é o desinteresse pela leitura, muitas vezes por não estarem completamente alfabetizados."

Sobre quais gêneros textuais ela costuma utilizar em suas aulas, a fim de desenvolver atividades de leitura, interpretação e compreensão, ela registrou que usa poemas, tirinhas, textos informativos, cartas entre outros. Para a Professora 2, 'Estratégias de Leitura' "são as várias formas de se apresentar um texto ao educando, poderia ser através de música, leituras em grupo, jogos, declamações, ilustrações, leitura silenciosa elou dramatização entre outros.” A professora não relatou suas estratégias de leitura utilizadas em suas aulas. 
Ao ser questionada sobre qual a forma com que ela trabalhava as estratégias de leitura, ou se era possível perceber que os(as) alunos(as) estavam conseguindo avançar e apresentar resultados nas atividades que requerem compreensão e interpretação leitora, a professora 2 relatou apenas que "Sim, percebo sensível melhora." Na questão sobre como trabalha as estratégias de leitura em sala de aula e como aplica diferentes gêneros textuais, ela respondeu: "A proposta Curricular Municipal traz vários gêneros textuais a serem trabalhados, nos diferentes níveis, sendo assim à medida que estes gêneros textuais vão se apresentando as diferentes estratégias citadas no item 12 irão sendo utilizadas conforme a necessidade e o momento".

Para a Professora 2, leitura significativa é "Uma leitura significativa é aquela em que o educando consiga penetra no contexto do enredo e tornando parte dele, vivenciando a experiência o texto e estudo." Quando perguntada sobre a questão de que se é possível medir a capacidade de compreensão leitora de um(a) aluno(a), ela respondeu que "sim, dependendo do nível em que o educando esteja. Quando ele consegue se apropriar das informações que o texto em estudo lhe apresenta."

\section{CONSIDERAÇÕES PRELIMINARES ENTRE AS DUAS PROFESSORAS:}

Diante das respostas das duas docentes, a acadêmica constatou algumas semelhanças e que podem auxiliar ou, ao menos, dar algumas pistas sobre a condução de seu trabalho desenvolvido nas séries selecionadas. Primeiramente, ambas trabalham na mesma unidade escolar há mais de 15 anos. Ambas alegam trabalhar com os gêneros textuais, seguindo a Proposta Curricular de Içara.

Em relação ao foco desta pesquisa, sobre as estratégias de leitura, foi possível identificar que uma trabalha com leitura silenciosa e oral, a outra não relatou como utiliza suas estratégias de leitura. Ou seja, para as professoras em questão, ainda está muito vago o que são estratégias de leitura, pois quando questionadas, as duas não souberam responder. Ambas alegaram que usam o laboratório de informática com uso de softwares, como são jogos ilustrativos os(as) alunos(as) se interessam mais para obter uma melhor compreensão dos(as) estudantes. Além do desinteresse e das dificuldades pela leitura ser bem grande, a maioria dos

Saberes Pedagógicos, Criciúma, v. 2, nº1, janeiro/junho 2018.- Curso de Pedagogia- UNESC 
casos por não estarem alfabetizados, gera grande problema para as professoras, pela dificuldade de o(a) aluno(a) interpretar o que leu, ou até mesmo produzir algo.

Sobre o uso de gêneros textuais, as duas professoras comentaram sobre os mesmos exemplos: trabalham com poemas, tirinhas, fábulas, textos informativos, cartas. Como a autora do artigo trabalha na escola, percebeu que as docentes só seguiram o que ali falaram, pois é como se esses gêneros fossem obrigatórios, uma vez que constam na Proposta Curricular de Içara.

Sobre a questão abordada na entrevista, em relação à possibilidade de medir a capacidade da compreensão leitora, o que mais chamou a atenção foi que a Professora 2 disse que "sim, vai depender do nível que cada educando esteja, pois se consegue entender o que o texto quer dizer, ele se apropria da informação e consegue desenvolver". Já a Professora 1 disse que "é algo bem complexo, depende da turma e do tipo de texto".

Em relação às respostas mencionadas, ficou claro que diante de questionamentos teóricos aliados às práticas sobre a leitura significativa, que o(a) aluno(a) tem que ver como uma atividade de busca, onde ele(a) próprio(a) consiga absorver o contexto da leitura. Quando se fala em estratégias de leitura, as docentes são conseguem estender muito o assunto, o que leva a acreditar que seja por falta de informações, pois foi percebido que a estratégias utilizadas em comum é apenas a leitura silenciosa.

Diante das respostas das professoras, percebeu-se que os gêneros textuais usados são seguidos pela Proposta Curricular do Município, onde usam poemas, fábulas, histórias em quadrinhos, receitas, textos informativos, cartas. Podemos, então, concluir que os gêneros textuais estão sendo utilizados em sala de aula, não exatamente todos, mas em grande maioria. A leitura na escola está inserida de forma que o aluno lê para aprender e desenvolver as questões básicas para escrever e ler, transformando as informações adquiridas em conhecimento, seja vivenciando ou só por experiências vivenciadas em sala de aula.

\section{CONSIDERAÇÕES FINAIS}

Esta pesquisa possibilitou à acadêmica refletir sobre a própria leitura, bem como sobre as Estratégias de leitura aplicadas no Ensino Fundamental I e sua importância no processo

Saberes Pedagógicos, Criciúma, v. 2, nº1, janeiro/junho 2018.- Curso de Pedagogia- UNESC 


\section{SABERES PEDAGÓGICOS}

Revista do Curso de Graduaçāo de Pedagogia - Unesc

ISSN 2526-4559
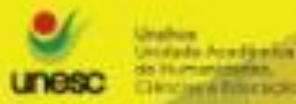

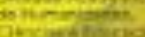

de ensino e aprendizagem, pois, em breve, virá a se tornar uma pedagoga. A partir da pesquisa, é possível acreditar que a escola está preocupada com a leitura dos(as) alunos(as), mas ainda parece muito presa somente ao momento da leitura. Esta afirmação se dá pela observação de que as turmas param de 30 a 45 minutos, fato que às professoras já lhes pareça o suficiente.

Também chamou a atenção, o fato de que o projeto da escola citado traz apenas um breve parágrafo, sem mostrar possibilidades inovadoras para levar o aluno a melhorar sua compreensão leitora. Os(As) professores(as) poderiam, por exemplo, trazer a questão da leitura com entusiasmo e criatividade, não apenas para seguir um cronograma, pois com estas atitudes não teremos crianças e adolescentes que se interessem por ela, mas como um ânimo fazendo com que a leitura se torne algo significativo na vida dos(as) estudantes.

Sobre o projeto da escola, não se vê falar muito da leitura, só de datas importantes, cronogramas, pois a cada ano o projeto da escola traz um tema. Esse ano o tema resgata os valores nos(as) alunos(as) como respeito, amor, paz, colaboração.

Mas, como o foco é em leitura, para a pesquisadora ficou algo vazio, já que no projeto apenas é citado um pequeno parágrafo sobre esta habilidade linguística que, na verdade, é só um da leitura. Poderíamos, então, concluir que a escola poderia em seu projeto falar mais sobre quais estratégias poderia usar, ser discutido em uma reunião pedagógica para os professores estivessem mais a par do assunto, tentando encontrar, juntos, melhor compreensão leitora dos(as) estudantes em suas áreas.

Quanto às redes sociais, a partir da pesquisa, foi descoberto que a escola possui um Blog, mas não está ativo desde 2010. A Unidade Escolar poderia usar essa ferramenta virtual como um incentivo à leitura, colocando livros disponíveis para a leitura via virtual, estimulando com dicas, postagens e, como estamos na era digital, poderia ser um caminho para criar o gosto pela leitura. A escola também possui um Facebook.

Para a instituição, essa ferramenta tem como foco disponibilizar os eventos da escola para os pais, recados importantes, mas é mais utilizando para socializar os registros com fotos de passeios de estudos dos(as) alunos(as), trabalhos feitos em sala de aula, dentre outros. No decorrer do dia a dia, os professores seguem uma rotina diária, onde a leitura significativa está entre todas as atividades, mas não é devidamente explorada. Eles precisam fazer com que

Saberes Pedagógicos, Criciúma, v. 2, nº1, janeiro/junho 2018.- Curso de Pedagogia- UNESC 
o(a) aluno(a) entenda que precisa, primeiramente, fazer a leitura sobre o assunto, transformando esse conhecimento em informação.

Partiu-se do princípio de que ler é um ato fundamental na vida de qualquer indivíduo e, como tal, a leitura precisa ser estimulada, incentivada e que, por isso, o papel da escola é mediar as experiências e conhecimentos da criança em relação aos conhecimentos acumulados histórica e socialmente pela humanidade. Através da pesquisa teórica e junto às respostas das educadoras, verificou-se que o gosto e o interesse pela leitura não é algo que já nasce com a criança, é fruto desse processo social, cultural e, por isso, a escola e os(as) professores(as) devem trabalhar na perspectiva de desenvolver o hábito de leitura junto aos(às) alunos(as), oportunizando momentos diversos, leituras variadas, contato com estilos e textos diversificados.

Ficou claro que as estratégias de leitura podem auxiliar na compreensão leitora dos(as) estudantes, e que existem inúmeras delas o que precisa é maior suporte teóricopedagógico para os(as) educadores(as), a fim de que seus(as) alunos(as) possam aplicá-las na vida e na escola. A pesquisa apontou, ainda, que para os(as) educadores(as) desenvolverem o gosto e o hábito da leitura em seus(as) educandos(as), eles(as) devem, primeiramente, ampliar sua própria percepção de mundo, de suas necessidades e, a partir disso, planejar suas estratégias.

Espera-se, portanto, que esta pesquisa possa contribuir para fazer com que outros(as) educadores(as) reflitam sobre suas práticas e continuem em busca de novas estratégias, estimulando e oportunizando ao(à) aluno(a) o acesso aos diversos gêneros textuais, capacitando-os como bons(as) leitores(as) que devem ser, ou seja, preparando-os(as) para a vida.

\section{REFERÊNCIAS}

BARROS, Aidil da Silveira Barros; LEHFELD, Neide Aparecida de Souza. Fundamentos de metodologia: um guia para iniciação científica. 2. ed. São Paulo: Makron Books, 2000.

BRASIL, Ministério da Educação e Cultura. Parâmetros Curriculares Nacionais: Língua Portuguesa. Brasília: 1997.

CAGNETI, Sueli de Souza; ZOTZ, Werner. Livro que te quero livre. Rio de Janeiro: Nórdica, 1986.

Saberes Pedagógicos, Criciúma, v. 2, nº1, janeiro/junho 2018.- Curso de Pedagogia- UNESC 


\section{SABERES PEDAGÓGICOS}

Revista do Curso de Graduaçāo de Pedagogia - Unesc

ISSN 2526-4559
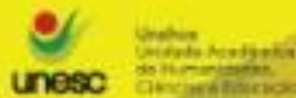

CAVÉQUIA, Márcia Paganini. Linguagem, Criação e Interação. São Paulo: Saraiva, 2002.

ELLIS, Andrew W. Leitura, escrita e dislexia: uma análise cognitiva. Trad. Dayse Batista. Porto Alegre: Artes Médicas, 1995.

EMMEL, I. et al. Caderno Pedagógico. Conteúdos e Metodologia da Linguagem. Florianópolis: UDESC/CEAD, 2003.

FREIRE, Paulo. A importância do ato de ler: em três artigos que se completam. São Paulo: Cortez, 1989.

IÇARA, Prefeitura Municipal de Içara. Secretaria Municipal de Educação, Ciência e

Tecnologia. Proposta Pedagógica Curricular de Içara: Ensino Fundamental. Içara, 2015.

KATO, M. A. No mundo da escrita: uma perspectiva psicolinguística. São Paulo: Ática, 1987.

LEFFA, V. J. Ensaios: Aspectos da leitura. Uma perspectiva psicolinguística. Porto Alegre: Sagra - D.C Luzzato, 1996.

MARCUSCHI, Luiz Antonio Marcuschi. Da fala para a escrita: atividades de retextualização. 2. ed. São Paulo: Cortez, 2007.

PINHEIRO, Ângela Maria Viera. Leitores julgados competentes pelas professoras. Porto Alegre: Artes Médicas, 1999.

PINHEIRO, José Maurício. Da iniciação científica ao TCC: uma abordagem para os cursos de tecnologia. Rio de Janeiro: Ciência Moderna, 2010.

RIZZATTI, E. et al. Caderno Pedagógico. Conteúdos e Metodologia da Linguagem II. Florianópolis: UDESC/CEAD, 2004.

SOLÉ, Isabel. Estratégias de leitura. Trad. Cláudia Schilling. 6. ed. Porto Alegre: Artmed, 1998. 